\title{
Intimate Relationship Dynamics and Changing Desire for Pregnancy Among Young Women
}

\author{
By Jennifer S. Barber, Warren Miller, Yasamin Kusunoki, Sarah R. \\ Hayford and Karen Benjamin Guzzo \\ CONTEXT: Although substantial research has focused on unintended \\ pregnancy among young women, less is known about the \\ circumstances under which pregnancy is desired. Whether a young \\ woman's pregnancy desire changes across her different relationships, \\ or over time within a relationship, has not been directly assessed.
}

METHODS: Data on intimate relationships and pregnancy desire were assessed weekly for 895 women aged 18-22 who participated in the Relationship Dynamics and Social Life study in a county in Michigan (2008-2012). Within-between logistic regression models were used to examine within-cluster and between-cluster differences-comparisons of a woman's pregnancy desire within a relationship over time as well as across a woman's different relationships.

This is the author manuscript accepted for publication and has undergone full peer review but has not been through the copyediting, typesetting, pagination and proofreading process, which may lead to differences between this version and the Version of Record. Please cite this article as doi: $10.1363 /$ psrh.12119 
RESULTS: Young women were more likely to desire pregnancy if they were in any relationship more intimate and committed than a casual relationship (odds ratios, 1.6-9.2); the odds of desiring pregnancy were also higher in long-term relationships rather than in short-term ones (2.1). In general, pregnancy desire increased over time as a relationship endured and became more serious. The odds of desiring pregnancy were lower among women with less educated, rather than equally educated, partners (0.7), while the odds were higher in nonmonogamous or violent relationships than in monogamous or nonviolent relationships (1.6 and 1.9, respectively).

CONCLUSIONS: Young women's pregnancy desire changes depending on their intimate relationship context, across the range of relationships they experience during the transition to adulthood.

Perspectives on Sexual and Reproductive Health, 2019, 51(3):TK, doi:TK

Self-reported pregnancy desire is a consistently strong predictor of pregnancy and fertility-related behaviors, including unintended pregnancy. ${ }^{1-3}$ Although researchers have long presumed that pregnancy desire changes as women progress through the life course, $, 4,5$ little empirical research has directly investigated how and why this 
change might occur. Because pregnancies are conceived in sexual partnerships, and because people tend to prefer to raise children in intimate relationships, changes in those relationships are likely to be a central component of change in pregnancy desire over time.

Young adulthood is a particularly important time in the life course for pregnancy and fertility-related behaviors and desires. Although $98 \%$ of all pregnancies among those younger than 15 and $89 \%$ among those aged 15-17 are unintended, the highest rates of unintended pregnancy are concentrated among young adults-individuals in their late teens and early 20s. The vast majority of women report zero desire for pregnancy around age $18,{ }^{6}$ but $95 \%$ of women report an ideal family size of at least two children.7 Understanding how women's desire for pregnancy evolves within and across intimate relationships is essential to understanding the frequent mismatch between pregnancy desire and pregnancy.

\section{THEORETICAL FRAMEWORK}

Previous research has demonstrated the utility of thinking about the motivational antecedents of childbearing as a multistep psychological sequence in which traits shape childbearing desires, which in turn affect childbearing intentions, which lead to the behaviors (e.g., sex and 
contraceptive use) meant to achieve or avoid a conception, pregnancy and birth-the traits-desires-intentions-behavior (TDIB) sequence., ${ }^{8,9}$ Internal and external factors intervene in the processes that link traits to desires, desires to intentions, and intentions to behavior. Particularly relevant for our analysis, the separate TDIB sequences of two individuals in a romantic or sexual dyad influence each other, through various interactive processes such as compromise, bargaining and dominane. ${ }^{8,10}$ For example, a woman might desire a pregnancy but not intend to get pregnant if her partner does not also desire a pregnancy.

Although our focus is on intimate relationships and pregnancy desire, we draw from research on intimate relationships and contraceptive use to develop our hypotheses because they are closely related; in the TDIB sequence, the desire for pregnancy is strongly linked to the instrumental behavior of contraceptive use. Our hypotheses also recognize that serious intimate relationships could lead to decreased contraceptive use for two reasons-because they increase the desire for pregnancy, or because they disrupt the link between a woman's desire to avoid pregnancy and its requisite behavior, contraceptive use, in some way.

\section{INTIMATE RELATIONSHIPS AND PREGNANCY DESIRE}


Some research has directly investigated whether intimate relationships affect the desire for pregnancy. For example, Edin and Kefalas's groundbreaking study of disadvantaged young mothers illustrated how "romance and dreams of shared children seem almost inevitably to go together"; that when a couple's relationship reaches the next level of commitment, their attitude toward pregnancy switches to "if it happens, it happens"; and that young women hope a pregnancy will convince their boyfriends to stop drinking, doing drugs and having sex with other women. ${ }^{11(\mathrm{pp} .28,30-31,42)}$ Higgins found that women in longerterm relationships were more open to the idea of an unintended pregnancy than women in new relationships..$^{12}$ In addition, three crosssectional quantitative studies demonstrated that desire for pregnancy is higher, and desire to avoid pregnancy is lower, in more serious than in less serious relationships. ${ }^{6,13,14}$

A larger body of research has indirectly focused on how intimate relationships affect pregnancy desire by examining variation in contraceptive use. Much of this research assumes, explicitly or implicitly, that variation in contraceptive use reflects variation in pregnancy desire. It consistently finds that couples in less serious relationships are more likely to use contraceptives, and to use them more consistently, than are couples in more serious relationships 
(although seriousness has been measured in various ways). Many of these studies focus on condom use, showing that it is more prevalent and consistent in less serious than in more serious relationships, ${ }^{15-17}$ and also that it is less prevalent in conflictual than in more harmonious relationships. ${ }^{14,16,18-20}$ Other studies have found that long-term couples are more likely to use hormonal contraceptives than are newly formed couples..$^{17,18,20}$

Despite the cross-sectional nature of most of these studies, relationship-level differences in contraceptive use have been interpreted as evidence of change in pregnancy desire over time. We build on this interpretation for our hypotheses about how pregnancy desire changes both across and within intimate relationships.

Previous research conceptualizes the character of intimate relationships in a wide variety of ways. On the basis of these studies, we identified two sets of relationship characteristics as being particularly relevant for contraceptive use and pregnancy desire: first, duration, intimacy and commitment; and second, conflict and asymmetry (or power imbalance between partners).

\section{Duration, Intimacy and Commitment}

Most studies of intimate relationships among young adults focus, to 
some extent, on their duration and how they change over time. For example, the "sawtooth" hypothesis posits that for sexual relationships, duration decreases perceived STD risk, and thus condom use, but also increases communication, which increases condom use or hormonal method use in place of condoms. ${ }^{16,19}$ Underlying this hypothesis is the assumption of a steady desire to avoid pregnancy regardless of duration: When relationships are new, condoms are used to prevent both pregnancy and STDs, but when the risk of STDs decreases, couples switch to other methods to continue preventing pregnancy. However, whether the desire to prevent pregnancy is actually consistent over time, or whether duration affects pregnancy desire or contraceptive use independent of other changes over time in the relationship, such as increasing intimacy or commitment, is unknown.

Although the type of relationship is sometimes conflated with duration, researchers agree that the former aspect is important, particularly because different types involve different levels of intimacy and commitment. Relationship types include, for example, casual, consistent, serious, dating, cohabiting and married, as well as more qualitative categories like "rosy outlook" or "cloudy outlook,"18 and typically incorporate measures of both intimacy and commitment. More serious types-intimate, committed or long-term-are associated 
with lower levels of contraceptive use relative to less serious types. ${ }^{18}$

There are several reasons why the desire for pregnancy might be greater in more committed, intimate and long-term relationships. First, raising a child is easier with the help of a partner, and a partner who is present and committed to the relationship is probably especially helpful. Second, women may view having a child as a way to cement their relationship with a partner who is sexually exclusive or who provides a high level of intimacy. ${ }^{11}$ Third, social norms proscribing nonmarital pregnancy may encourage pregnancy desire as relationships become more "marriage-like" (e.g., partners are monogamous, partners share residence).

In cross-sectional research on contraceptive use, hypotheses about intimacy, commitment and duration are typically intertwined because the most intimate and committed relationships are the most long term, and together, these attributes affect contraceptive use. Duration itself could be considered an aspect of commitment-couples who remain together have demonstrated their commitment, at least in some form. However, some aspects of duration may affect desire for pregnancy independent of intimacy or commitment. For example, social norms that discourage pregnancy too early within a new relationship may lead pregnancy desire to increase with relationship duration. Further, 
duration may capture unmeasured aspects of intimacy and commitment. Thus, we hypothesize that greater intimacy and commitment will be associated with increased desire for pregnancy, and that increasing duration will also be associated with increasing desire for pregnancy.

\section{Conflict and Asymmetry}

Researchers also agree that negative qualities of relationships are important determinants of contraceptive use.16,20 Most research categorizes these negative qualities as conflict or asymmetry, ${ }^{19}$ which are often intertwined. For example, the odds of physical violence are twice as high in churning relationships (those characterized by breaking up and reconciling) as in nonchurning relationships. ${ }^{21}$ Conflict and asymmetry are also correlated with intimacy, commitment and duration. For example, cohabitors experience more churning than noncohabitors, and churning relationships tend to last longer, overall, than nonchurning relationships. ${ }^{22}$

Although conflict and asymmetry have been consistently linked to reduced levels of contraceptive use, the link has been attributed to difficulty translating desire to avoid pregnancy into the requisite behaviors rather than to desire for pregnancy. In fact, conflict and 
asymmetry may be associated with greater desire for pregnancy, particularly if a couple sees a baby as a way to save a troubled relationship, ${ }^{11}$ a woman sees a pregnancy as a way to decrease violence or to lay claim to a partner who is nonmonogamous, ${ }^{11}$ or an older partner wants to get their younger partner pregnant.

However, conflict and asymmetry may also be associated with reduced pregnancy desire. For example, churning may be a sign that the partner has low long-term interest in intimacy or commitment, ${ }^{23}$ and thus would not make a reliable co-parent. Women may be less likely to desire pregnancy with a nonmonogamous partner who may impregnate someone else at the same time, or whose other relationship will interfere with his ability to parent their potential child. Having an older partner or experiencing partner-dominated decision making while dating may be an indicator of the future division of labor in the relationship. And because education is correlated with gendered attitudes and behavior, women may prefer more highly educated partners because it may indicate future egalitarianism. ${ }^{24}$

\section{Other Characteristics}

This study also examines differences in pregnancy desire across other variables that are associated with young adult intimate relationship 
experiences, and that may be associated with pregnancy desire. Because the vast majority of women in the United States want two children, ${ }^{7}$ children from a prior relationship likely dampen women's pregnancy desire. Blacks and economically disadvantaged young women may have greater pregnancy desire than nonblacks and less disadvantaged women at these ages, given their earlier intimate relationship and childbearing experiences. ${ }^{25,26}$ Highly religious young women postpone sexual debut, and likely want to postpone births at these young ages. ${ }^{27}$ Further, adolescent experiences with sex, contraceptive nonuse and pregnancy are strongly associated with subsequent contraceptive use, ${ }^{28}$ perhaps via pregnancy desire.

\section{Overall Approach and Goals}

Accurately capturing the dynamic interplay of pregnancy desire and intimate relationships during young adulthood requires frequent measurement of both; such data have only recently become available. ${ }^{29,30}$ The unique data we use-from the Relationship Dynamics and Social Life (RDSL) study-are from a longitudinal study of 895 young women in a county in Michigan who were followed for 2.5 years, and who reported at least one intimate relationship during the study period. Women were asked weekly about their intimate 
relationships and their desire for pregnancy in the upcoming month.

We make two contributions to understanding pregnancy desire among young adult women. First, we focus on multiple aspects of intimate relationships-intimacy, commitment, duration, conflict and asymmetry. Second, we take a dynamic approach to assess the extent to which differences in pregnancy desire are due to individual women changing over time, moving through the life course in different relationships with different partners, and the extent to which they are due to specific relationships changing and enduring over time.

\section{METHODS}

Data

The RDSL study is based on a random sample of 1,003 women, aged 18-19 at baseline, drawn from driver's license and personal state ID card $^{*}$ records in a racially and socioeconomically diverse Michigan county. The response rate was $84 \%$ overall $(94 \%$ of located respondents agreed to participate). Sixty-minute face-to-face baseline survey interviews conducted in March 2008-July 2009 were used to collect information on social and demographic characteristics and on attitudes and adolescent experiences related to pregnancy. Respondents were then invited to participate in a 2.5-year follow-up study with brief 
weekly surveys assessing their intimate relationships, contraceptive use, pregnancy desires and pregnancy experiences. Respondents were mailed $\$ 5$ in advance in a letter introducing the study, and were paid $\$ 30$ for the baseline interview. Additional incentives were $\$ 5$ per weekly interview for the first four weeks and \$1 per interview thereafter, with $\$ 5$ bonuses for on-time completion of five interviews in a row.

Nine hundred and ninety-two of the baseline interview respondents (99\%) agreed to participate in the follow-up study; $95 \%$ of those completed at least two surveys after the baseline interview, 84\% continued for at least six months, 79\% for at least 12 months and $75 \%$ for at least 18 months. The follow-up study concluded in January 2012, and yielded 58,594 weekly interviews. We analyzed data from the 895 women who ever reported a partner in their weekly interviews.

\section{Measures}

-Pregnancy desire. In each weekly survey (when not pregnant), women were asked, "How much do you want to get pregnant during the next month?" Respondents chose a number between 0 ("not at all want") and 5 ("really want"). Because women gave any nonzero answer in only $10 \%$ of weekly interviews, and because prior research has shown 
that any nonzero desire is a strong predictor of subsequent pregnancy, ${ }^{2}$ we used a dichotomized version of this measure coded 1 for any nonzero response and 0 for a zero response.

-Intimate relationship characteristics. Each week, a series of questions ascertained whether the respondent had an intimate partner of any kind during the prior week. For a new partner (one not discussed in a prior interview), the respondent provided initials or a nickname.* If the partner was different from the partner in the most recent interview, but had been discussed in a prior interview, respondents chose from their list of initials and nicknames; hence interviews about the same partner were linked across time regardless of breaks.

To measure intimacy and commitment, the RDSL survey did not ask respondents to label their relationships, but rather posed a series of questions. Respondents were first asked whether they were engaged to be married or married to their partner, whether they lived in a place "separate from where your partner lives" and how many nights they spent "all night sleeping in the same bed" during the prior week. Answers to these questions defined the three most serious (intimate and committed) relationships: engaged or married, ${ }^{*}$ cohabiting and "stayovers" (slept in the same bed three or more nights out of the prior seven $^{31}$ ). Two additional questions - whether they "spent a lot of time" 
with their partner during the prior week (intimacy), and whether they had "agreed to only have a special romantic relationship with each other, and no one else" (commitment)-were used to define four additional relationship categories: committed dating-a lot of time together and committed to being monogamous; infrequent committed dating-not a lot of time together, but committed to being monogamous; uncommitted dating-a lot of time together, not committed; and casual-not a lot of time together and not committed. One additional indicator of intimacy was assessed with the following question: "Did you have sexual intercourse with [partner]? By sexual intercourse, we mean when a man puts his penis into a women's vagina."* For each week, responses were coded 1 when sexual intercourse occurred, and 0 when it did not.

Relationship duration indicated the total of all weeks spent with the partner, including time before and after breakups, coded in exact years. We also included respondents' age, to distinguish between the passage of time in general and the passage of time within the relationship; age was determined from the driver's license and personal ID card records used to select the sample and was coded in exact years.

The RDSL data set includes seven weekly indicators of conflict and asymmetry. We constructed a measure coded 1 for churning if the 
couple broke up and reconciled. If a respondent had a concurrent sexual partner (other than her focal partner), or thought her partner had another sexual partner, nonmonogamy was coded 1. Partnerdominated decision making - "Who decides what to do or where to go when you go out?" - was coded -1 for the respondent, 1 for the partner and 0 for both. The presence of threats was coded 1 if the partner threatened her with violence, and physical assault was coded 1 if her partner pushed her, hit her or threw something at her that could hurt.

Each of the intimate relationship characteristics was coded in three ways: first, as a time-varying weekly indicator-for example, whether the relationship was a stayover, or whether it included physical violence during the prior week - with duration measured in weekly increments; second, as a time-invariant relationship-level indicator-for example, whether the relationship was ever a stayover, or whether the relationship had ever involved physical violence (with duration coded at its maximum for each relationship); and third, as a time-invariant woman-level indicator-for example, whether she had ever experienced a stayover relationship, or whether she had ever had sexual intercourse (with duration coded as the mean of all of the woman's relationships).

We also used two additional time-invariant relationship-level 
indicators of asymmetry. Age difference was coded in exact years by subtracting the respondent's age from the partner's age. We compared women's educational attainment or enrollment with their partner's education at the beginning of their relationship to create a threecategory measure of educational asymmetry: partner has more education, equal education or partner has less education. Partner's education was reported categorically, but we converted the categories to years: dropped out of high school (11 years), graduated from high school but not enrolled in postsecondary education (12 years), enrolled in postsecondary education (14 years) and graduated from a four-year university (16 years).

- Partner variables. We included two time-invariant partner control variables. Partner's education was coded in years. We used a mutually exclusive, exhaustive four-category variable to indicate whether and which individual in the relationship had had a prior birth: neither, the couple together, the woman or the partner.

-Individual variables. We used several time-invariant woman-level control variables as well. Race was measured with a dichotomous variable-black or nonblack ${ }^{*}$-based on self-selected race. Latina women (determined by a separate question) were coded by race.* Religiosity was assessed by the question, "How important, if at all, is 
your religious faith to you?" "Highly religious" is a dichotomous variable indicated by responses of "very important" or "more important than anything else."

Six measures were used to examine respondents' social and demographic background. Four dichotomous indicators of childhood disadvantage were: respondent did not grow up with two parents, biological mother had a teenage birth, mother's education was less than high school and family received public assistance during respondent's childhood. Because many respondents were still enrolled in high school and few had completed any postsecondary education at baseline, we used high school grade point average as a proxy for educational success and potential for educational attainment. A dichotomous measure indicated whether respondents were currently receiving any type of public assistance at baseline. Finally, four dichotomous baseline measures of adolescent (prestudy) experiences related to sex and pregnancy were included in the models: being age 16 or younger at first sexual intercourse, having had more than two sex partners, ever having had sex without contraceptives and having had a prior pregnancy.

Due to the intensive nature of the data collection, we also included a measure of the total number of weekly surveys completed, to control for repeated assessment. 
- Sensitivity analysis. We also conducted a sensitivity analysis using an additional measure of desire related to pregnancy. The young women were asked about their desire to avoid pregnancy - "How much do you want to avoid getting pregnant during the next month?"-with the same $0-5$ response options used on the pregnancy desire measure. We estimated models of their desire to avoid pregnancy, using a dichotomous indicator for anything other than the strongest desire to avoid one (score of $0-4)$.

\section{Analysis}

We calculated proportions for dichotomous measures of pregnancy desire, intimate relationships and control variables. We present proportions at three levels: weeks (the proportion of the weekly interviews coded 1), relationships (the proportion of the relationships with any week coded 1) and women (the proportion of women coded 1 during any week in any of their relationships).

For the seven continuously coded variables, we calculated means and standard deviations. Age and relationship duration varied weekly in our models, but for ease of interpretation, we present the mean age for the 895 women at the time of the baseline interview, and the mean total duration for the 2,564 relationships (when they ended or were right- 
censored). Partner-dominated decision making also varied weekly; we present the mean across weeks, across relationships and across women. Age difference and partner's education varied across relationships, but not over time within relationships; we present those means for the 2,564 relationships. And, finally, high school grade point average and the total number of weekly surveys completed varied only across women.

Next, we estimated logistic regression models for our dichotomous outcome, pregnancy desire. We used the within-between specification for clustered data (using the command xthybrid in Stata), applied separately to two types of clustering in the data: relationships clustered within women (woman level) and weekly interviews clustered within relationships (relationship level). ${ }^{34-36}$ This method is called "withinbetween" because separate coefficients are estimated for within-cluster differences (i.e., each unit's deviation from its cluster-level mean) and between-cluster differences (i.e., differences across the cluster-level means).

The two types of clustering permit the testing of two types of hypotheses: comparisons across a woman's different relationships, and comparisons within a relationship across time. For example, we hypothesized that a woman would have higher odds of pregnancy desire in her more intimate and committed relationships than in her 
other less intimate and committed relationships (within-woman difference), and that within a relationship, pregnancy desire would be higher during more intimate or committed times than during less intimate or committed times (within-relationship difference). As in fixed-effects models, the within-woman coefficients are independent of the effect of any unmeasured stable characteristics of women that increase their probability of entering serious relationships at a young age and their probability of desiring pregnancy at a young age (e.g., unmeasured aspects of disadvantaged socioeconomic background, low educational expectations). The within-relationship coefficients are independent of the effect of any unmeasured stable characteristics of the relationship that decrease its probability of becoming serious and of including pregnancy desire (e.g., having a partner with mental health problems might decrease the duration of a relationship and decrease pregnancy desire, or a partner with negative attitudes toward family formation may eschew commitment and dampen pregnancy desire).

The between-cluster coefficients for both models are difficult to interpret because they do not control for within-cluster differences, nor do they correspond to any of our hypotheses. Thus, we do not describe those coefficients, but include them in Table 2 for reference.

Unlike fixed-effects models, the within-between specification 
combines aspects of fixed-effects models with random-effects models, and allows the inclusion of random intercepts for stable cluster-level variables. (This is why it is sometimes called a "hybrid" approach.) We included random effects for all of the control variables described above. Regression findings are presented as odds ratios (exponentiated coefficients). In both models, the unit of analysis is the person-week. Our models use an analytic sample of 32,754 weekly observations from 895 ever-partnered women who reported a total of 2,564 unique partners.

\section{RESULTS}

\section{Sample Characteristics}

Thirty-four percent of respondents reported any desire for pregnancy during the study period; they reported that desire in $17 \%$ of their intimate relationships, and in $10 \%$ of the total weekly interviews (Table $1)$.

Women experienced a wide range of relationships in terms of intimacy and commitment. Thirty percent were engaged or married, $45 \%$ cohabited and $51 \%$ had a stayover relationship; $75 \%$ reported a committed dating relationship, $64 \%$ an infrequent but committed dating relationship, 51\% an uncommitted dating relationship and 54\% 
at least one casual relationship. The average relationship duration was about a year and a half (which is an underestimate because many relationships were ongoing when the study ended), and the respondents' average age was 19. Overall, $87 \%$ of women reported having had heterosexual sexual intercourse during the study period. They had heterosexual sex in $65 \%$ of their intimate relationships, and reported it in $54 \%$ of the weekly interviews.

Conflict and asymmetry in relationships were relatively common. For example, one-quarter of relationships involved churning (and $46 \%$ of all women experienced this), and 19\% of relationships involved nonmonogamous partners (reported by $28 \%$ of women). The mean score for partner-dominated decision making across relationships was 0.05-slightly more partner-dominated than equal-and the mean across women was even more so, at 0.21. Overall, a substantial proportion of women experienced almost all of the relationship situations we examined, even those that were rarely observed across the weekly interviews. For example, although threats of assault and physical assault occurred in only $1 \%$ (each) of the weekly interviews, $6 \%$ of relationships involved each of these types of violence, and $14 \%$ and $17 \%$ of women, respectively, ever had these experiences. On average, partners were 2.2 years older than respondents. 
Our sample of ever-partnered 18- and 19-year-old women from the RDSL study resembles the nationally representative sample of 18 - and 19-year-old women in the National Survey of Family Growth (NSFG), with a few exceptions. ${ }^{37}$ Black women are overrepresented in the RDSL study sample compared with the U.S. population (34\% vs. $16 \%$ ). A greater proportion of women in the RDSL study than of women in the NSFG consider themselves highly religious ( $57 \%$ vs. $45 \%$ ), have a mother who gave birth as a teenager (36\% vs. $29 \%)$ and experienced teenage pregnancy themselves ( $26 \%$ vs. $19 \%)$. A slightly higher proportion of women in the RDSL study grew up in a household without two parents ( $47 \%$ vs. $43 \%)$. A smaller proportion of women in the RDSL study than of women in the NSFG had had sex before age 17 (53\% vs. $60 \%)$.

\section{Multivariate Findings}

There were many within-woman differences across their relationships, and many within-relationship differences across time (Table 2). The pattern of within-woman and within-relationship differences regarding intimacy, commitment and duration was much stronger and more consistent than the pattern for conflict and asymmetry.

Model 1 found that every measure of intimacy and commitment was 
strongly associated with elevated odds of desiring pregnancy. A woman had dramatically higher odds of desiring pregnancy when she was in an engaged or married relationship than when she was in a casual relationship (odds ratio, 9.2), as well as when she was in any other type of more intimate and committed relationship (1.6-3.7). A woman also had twice the odds of desiring pregnancy in her sexual relationships than in her nonsexual relationships (2.0).

Model 2 demonstrated that changes in intimacy and commitment within a relationship were related to changing pregnancy desire, as well. The within-relationship estimates showed elevated odds of pregnancy desire when a relationship involved engagement or marriage (odds ratio, 6.3), cohabiting (2.5), stayover (3.0), committed dating (1.7) or infrequent committed dating (2.1), relative to other times in that same relationship that were casual. The odds of desiring pregnancy were also greater while the relationship was sexually active $(2.2) .^{*}$

In terms of duration, a woman was more likely to desire pregnancy in her longer-lasting relationships than in her shorter relationships (model 1, odds ratio, 2.1 per year), and within a relationship, she was more likely to desire pregnancy as it grew in duration (model 2, 4.8), independent of levels of intimacy and commitment. The odds ratios for 
duration were large, but the negative association between duration squared and pregnancy desire (0.8 in both models) showed that as a relationship endured, the positive association between duration and pregnancy desire decreased. Further, independent of intimacy, commitment and duration, women became less likely to desire a pregnancy as they aged (0.4).

Conflict and asymmetry were also associated with pregnancy desire, independent of intimacy, commitment and duration. Model 1 showed that a woman had higher odds of pregnancy desire in her relationships that were nonmonogamous or that included physical assault than in her monogamous or nonviolent relationships (odds ratio, 1.6 and 1.9, respectively). Model 2, however, found that changing levels of conflict and asymmetry within a relationship were not associated with changes in pregnancy desire. Women had lower odds of pregnancy desire with partners who were less educated, rather than similarly educated, than themselves (0.7), independent of the partner's education level, but age difference was not related to pregnancy desire.

In addition, some of the partner measures that vary across relationships, but not within relationships (and thus are random effects, rather than within or between effects in Model 2), were significant associated with pregnancy desire. For the most part, these results were 
consistent with the "within effects" in Model 1, which also compared across relationships. The one exception was partner's overall education: In model 2, relationships with highly educated partners were less likely to include pregnancy desire than relationships with less educated partners (odds ratio, 0.6). In model 1, this association was not significant.

When we examined partner and individual control variables, women had a reduced likelihood of reporting pregnancy desire in their relationships that involved children-whether shared births or their own (odds ratios, 0.4 and 0.2, respectively). Stable woman-level control variables that were associated with elevated odds of pregnancy desire (independent of intimacy, commitment, duration, conflict and asymmetry) included being black (2.5), receiving public assistance during childhood (2.7) and having sex without birth control during adolescence (2.5). Highly religious respondents, on average, had lower odds of pregnancy desire than their less religious counterparts (0.5).*

\section{Sensitivity Analysis}

The models in our sensitivity analysis generated results very similar to those presented in Table 2, with a few exceptions. In model 1 (within woman), the estimate for nonmonogamy was not significant, but the 
estimates for partner-dominated decision making and physical assault were significant and positively associated with the desire to avoid pregnancy. In model 2 (within relationship), being in a committed dating relationship was not significant, but all other estimates matched those in Table 2.

\section{DISCUSSION}

Our analyses showed large differences in pregnancy desire across a woman's different relationships; women had dramatically higher odds of desiring a pregnancy in more serious-intimate, committed and long-term-relationships than in less serious ones. Further, the odds of pregnancy desire increased within young women's relationships, as the relationship endured and became more intimate and committed. Our fixed-effects approach ensured that the observed increase over time was independent of any unmeasured stable individual-level traits that may be associated with pregnancy desire and entering longer, more serious relationships during young adulthood. The increase was also independent of any stable unmeasured relationship characteristics associated with how long a relationship endured, or how intimate and committed it became, as well as with pregnancy desire. Thus, our analyses suggest a causal link between serious relationships and 
pregnancy desire.

Another pattern in these findings is that a woman had higher odds of desiring a pregnancy in her conflictual or asymmetric relationshipsnonmonogamous and physically violent-than in less conflictual or asymmetric relationships. Our results are consistent with crosssectional research showing that conflict and asymmetry were associated with lower levels of contraceptive use, but that those associations were smaller and less consistent than those for intimacy, commitment and duration..$^{21}$

In the present analysis, the positive association between conflict and asymmetry and pregnancy desire was also independent of stable individual-level characteristics, and thus was not because of reciprocal effects, such as young women who desire pregnancy entering more conflictual or asymmetric relationships, or tolerating (and thus less likely to dissolve) conflictual or asymmetric relationships. However, these variables were not associated with changing pregnancy desire within a relationship, which suggests that the conflict or asymmetry itself does not produce desire for pregnancy. Rather, we speculate that nonmonogamous and physically violent relationships have other characteristics that are associated with pregnancy desire. For example, research has shown that violent young men are more likely than their 
nonviolent counterparts to want their girlfriends to get pregnant. ${ }^{38}$ In addition, Edin and Kefalas observed that young women with undesirably behaving partners hope that a pregnancy will cause them to settle down and start a family. ${ }^{11}$ Although our results are consistent with research showing that conflictual and asymmetric relationships have lower rates of contraceptive use than nonconflictual and symmetric relationships, they are not consistent with our hypotheses that conflict and asymmetry would be associated with reduced pregnancy desire. However, recall that our sensitivity analyses of the desire to avoid pregnancy showed that partner-dominated decision making and physical violence were also associated with elevated odds of wanting to avoid a pregnancy. Further research will be required to disentangle the complex links between conflictual and asymmetric relationships and pregnancy-related motivations and connected behaviors.

Women have a lower likelihood of desiring pregnancy in their relationships with men who are less educated than themselves than in their relationships with equally or more educated men, independent of the level of their partner's education. The RDSL study data set cannot tell us about the mechanisms that might produce this specific link between asymmetry and pregnancy desire, but we speculate that 
women may desire pregnancy with similarly or more educated men because of education's correlation with more egalitarian attitudes toward household chores and childrearing. ${ }^{27}$

\section{Limitations}

Although the RDSL sample was randomly selected and population based, it is representative only of women in a single county in Michigan, in the age range 18-22, and up through 2012. The county has a small number of Latinas; we hope our research motivates future studies on populations that include more Latinas. However, in terms of cohabitation, marriage, age at first birth, completed family size, nonmarital childbearing and teenage childbearing, Michigan is not an outlier, ${ }^{39}$ and we do not expect the underlying associations we examined here to vary across regions, or to have changed much since 2012. It may be, however, that these associations would be quite different for women older than 22 .

The RDSL study also did not interview male partners, and thus lacks their point of view. Although the survey question about pregnancy desire was meant to assess women's own desire for pregnancy, it is unclear how women interpreted the question. Men's pregnancy desire is important for our understanding of women's pregnancy desire, and 
according to the TDIB framework,, 90 particularly important for a full understanding of how pregnancy desire leads to pregnancy (or not).

\section{Conclusions}

Previous research has not adequately explored the important role of increasing desire for pregnancy in intimate relationships. Although our findings were consistent with research emphasizing couples' decreasing motivation to avoid pregnancy over time and the difficulty of maintaining consistent contraceptive use over the long term, ${ }^{13,17}$ the RDSL respondents also became increasingly likely to desire pregnancies, even at these young ages, as their relationships endured and grew more intimate and committed.

Interventions aimed at improving intimate relationships, such as those for co-parenting young adults, ${ }^{41}$ may inadvertently increase the desire for early pregnancy, and those that help young women achieve their family planning goals may increase pregnancy rates.

Further, although long-acting reversible contraceptive methods are increasingly recommended by clinicians, and are desirable to some young women-particularly students, the very young and those without a serious partner ${ }^{14}$-other individuals may experience sudden increases in pregnancy desire that make these methods less appealing. 
For young women in relationships that move at what Edin and Kefalas described as "lightning speed,"11(p.30) even if they don't desire pregnancy at the time of their clinic visit, long-acting methods may quickly become incongruent with their family formation goals. Clinicians should recognize that young women's desire for pregnancy can change rapidly, and should account for this when discussing the positive and negative aspects of specific contraceptive methods. 


\section{FOOTNOTES}

FN A

*Personal state ID cards are issued by the Secretary of State in Michigan for those who need a state-issued identification card (e.g., for public benefits, air travel) but are not licensed to drive. Approximately $25 \%$ of the sampling frame was from ID cards, and $75 \%$ was from driver's licenses. At the time of the survey, the University of Michigan's Survey Research Center sampling statisticians estimated that the combined lists represented 95\% of the 18- and 19-year-old women represented by U.S. census data.

FN B

*In the rare weeks in which a respondent identified more than one partner, only the most important or most serious one was discussed in detail.

FN C

*We combined these two categories because married weeks were relatively infrequent ( $5 \%$ of partnered weeks) and because the odds ratios for the two groups separately were similar.

FN D

*We focused on heterosexual sexual intercourse because it leads to pregnancy. Most young women in the RDSL study, regardless of sexual orientation, had had heterosexual sex at some point (source: Ela EJ and Budnick J, Non-heterosexuality, relationships and young women's contraceptive behavior, Demography, 2017, 54(3):887-909, http://dx.doi.org/10.1007/s13524-017-0578-y).

FN E 
*Only 16 women reported another racial identity (American Indian or Asian); we combined this small group with white women. Deleting them did not change our results.

\section{FN F}

*The RDSL study included fewer than 80 Latinas, which preluded analyzing them as a separate category.

FN G

*The relationship-level cross-tabulation of engaged or married and being threatened yielded only 43 relationships, 35 of which included pregnancy desire. Excluding these variables from the model (i.e., combining engaged or married with cohabiting and combining threats with physical assault) removed the very small cells (and the very large odds ratios for between-relationship effects), but changed the other numbers in the table very little. Thus, we present those two estimates with the warning that they are based on a small number of relationships.

\section{FN H}

*Those same variables were considered at the relationship level in Model 2, meaning that individual-level characteristics were considered relationship-level characteristics, and the random effects accounted for weeks clustered within relationships but not relationships clustered within women. So, for example, sexually experienced young women (having had more than two partners in adolescence) contributed more relationships to the analysis than did less experienced young women, ${ }^{27}$ but the model treated each relationship as an independent observation. Because this may bias the random effects, we did not interpret them. 


\section{REFERENCES}

1. Chuang $\mathrm{CH}$ et al., Predicting pregnancy from pregnancy intentions: prospective findings from the Central Pennsylvania Women's Health Study (CePAWHS), Women's Health Issues, 2009, 19(3):159-166, http://dx.doi.org/10.1016/j.whi.2009.02.001.

2. Miller WB, Barber JS and Gatny $\mathrm{HH}$, The effects of ambivalent fertility desires on pregnancy risk in young women in the USA, Population Studies, 2013, 67(1):25-38, http://dx.doi.org/10.1080/00324728.2012.738823.

3. Moreau $\mathrm{C}$ et al., Effect of prospectively measured pregnancy intentions on the consistency of contraceptive use among young women in Michigan, Human Reproduction, 2013, 28(3):642-650, http://dx.doi.org/10.1093/humrep/des421.

4. Williams L, Abma J and Piccinino LJ, The correspondence between intention to avoid childbearing and subsequent fertility: a prospective analysis, Family Planning Perspectives, 1999, 31(5):220-227, http://dx.doi.org/10.2307/2991569.

5. Barber JS, Kusunoki Y and Gatny HH, Design and implementation of an online weekly journal to study unintended pregnancies, Vienna Yearbook of Population Research, 2012, 9:327-334, http://dx.doi.org/10.1553/populationyearbook2011s327.

6. Weitzman A et al., Desire for and to avoid pregnancy during the transition to adulthood, Journal of Marriage and the Family, 2017, 79(4):1060-1075, http://dx.doi.org/10.1111/ jomf.12396.

7. Gao G, Americans' ideal family size is smaller than it used to be, Fact Tank, 2015, http://www.pewresearch.org/fact-tank/2015/05/08/ideal-size-of-the-american-family/.

8. Miller WB and Pasta DJ, The motivational substrate of unintended and unwanted pregnancy, Journal of Applied Biobehavioral Research, 2002, 7(1):1-29, http://dx.doi.org/ 10.1111/j.1751-9861.2002.tb00073.x.

9. Miller WB, Childbearing motivations, desires and intentions: a theoretical framework, Genetic, Social and General Psychology Monographs, 1994, 120(2):223-258. 
10. Miller WB, Severy LJ and Pasta DJ, A framework for modelling fertility motivation in couples, Population Studies, 2004, 58(2):193-205, http://dx.doi.org/10.1080/ 0032472042000213712.

11. Edin K and Kefalas M, Promises I Can Keep, Berkeley, CA: University of California Press, 2005.

12. Higgins JA, Pregnancy ambivalence and long-acting reversible contraceptive (LARC) use among young adult women: a qualitative study, Perspectives on Sexual and Reproductive Health, 2017, 49(3):149-156, http://dx.doi.org/10.1363/psrh.12025.

13. Carter $\mathrm{M}$ et al., Relationship characteristics and feelings about pregnancy among black and Puerto Rican young adults, Perspectives on Sexual and Reproductive Health, 2013, 45(3):148-156, http://dx.doi.org/10.1363/4514813.

14. Raine TR et al., Contraceptive decision-making in sexual relationships: young men's experiences, attitudes and values, Culture, Health $\mathcal{E}$ Sexuality, 2010, 12(4):373-386, http://dx.doi.org/10.1080/13691050903524769.

15. Hock-Long L et al., Condom use with serious and casual heterosexual partners: findings from a community venue-based survey of young adults, AIDS and Behavior, 2013, 17(3):900-913, http://dx.doi.org/10.1007/s10461-012-0177-2.

16. Manning WD et al., Relationship dynamics and consistency of condom use among adolescents, Perspectives on Sexual and Reproductive Health, 2009, 41(3):181-190, http://dx.doi.org/10.1363/4118109.

17. Reed J et al., Consistent and inconsistent contraception among young women: insights from qualitative interviews, Family Relations, 2014, 63(2):244-258, http://dx.doi.org/ 10.1111/fare.12058.

18. Manlove J et al., Relationship types and contraceptive use within young adult dating relationships, Perspectives on Sexual and Reproductive Health, 2014, 46(1):41-50, http://dx.doi.org/10.1363/46e0514. 
19. Manlove J et al., Relationship characteristics and contraceptive use among young adults, Perspectives on Sexual and Reproductive Health, 2011, 43(2):119-128, http://dx.doi.org/ 10.1363/4311911.

20. Wildsmith E, Manlove J and Steward-Streng N, Relationship characteristics and contraceptive use among dating and cohabiting young adult couples, Perspectives on Sexual and Reproductive Health, 2015, 47(1):27-36, http://dx.doi.org/10.1363/47e2515.

21. Halpern-Meekin S et al., Relationship churning, physical violence and verbal abuse in young adult relationships, Journal of Marriage and the Family, 2013, 75(1):2-12, http://dx.doi.org/10.1111/j.1741-3737.2012.01029.x.

22. Halpern-Meekin S et al., Relationship churning in emerging adulthood: on/off relationships and sex with an ex, Journal of Adolescent Research, 2013, 28(2):166-188, http://dx.doi.org/10.1177/0743558412464524.

23. Manning WD et al., The complexities of adolescent dating and sexual relationships: fluidity, meaning(s) and implications for young adults' well-being, New Directions for Child and Adolescent Development, 2014, 2014(144):53-69, http://dx.doi.org/ 10.1002/cad.20060.

24. Cotter D, Hermsen JM and Vanneman R, The end of the gender revolution? Gender role attitudes from 1977 to 2008, American Journal of Sociology, 2011, 117(1):259-289, http://dx.doi.org/10.1086/658853.

25. Kusunoki $Y$ et al., Black-white differences in sex and contraceptive use among young women, Demography, 2016, 53(5):1399-1428, http://dx.doi.org/10.1007/s13524-016-0507-5.

26. Manlove J et al., Racial and ethnic differences in the transition to a teenage birth in the United States, Perspectives on Sexual and Reproductive Health, 2013, 45(2):89-100, http://dx.doi.org/10.1363/4508913.

27. Manlove J et al., Pathways from family religiosity to adolescent sexual activity and contraceptive use, Perspectives on Sexual and Reproductive Health, 2008, 40(2):105-117, 
http://dx.doi.org/10.1363/4010508.

28. Manlove J, Ryan S and Franzetta K, Contraceptive use patterns across teens' sexual relationships: the role of relationships, partners and sexual histories, Demography, 2007, 44(3):603-621, http://dx.doi.org/10.1353/dem.2007.0031.

29. Hayford SR, The evolution of fertility expectations over the life course, Demography, 2009, 46(4):765-783, http://dx.doi.org/10.1353/dem.0.0073.

30. Sennott $C$ and Yeatman S, Stability and change in fertility preferences among young women in Malawi, International Perspectives on Sexual and Reproductive Health, 2012, 38(1):34-42, http://dx.doi.org/10.1363/3803412.

31. Jamison TB and Ganong L, "We're not living together": stayover relationships among college-educated emerging adults, Journal of Social and Personal Relationships, 2011, 28(4):536-557, http://dx.doi.org/10.1177/0265407510384897.

32. Kusunoki $\mathrm{Y}$ and Upchurch DM, Contraceptive method choice among youth in the United States: the importance of relationship context, Demography, 2011, 48(4):1451-1472, http://dx.doi.org/10.1007/s13524-011-0061-0.

33. Higgins JA, Popkin RA and Santelli JS, Pregnancy ambivalence and contraceptive use among young adults in the United States, Perspectives on Sexual and Reproductive Health, 2012, 44(4):236-243, http://dx.doi.org/10.1363/4423612.

34. Schunck R and Perales F, Within- and between-cluster effects in generalized linear mixed models: a discussion of approaches and the xthybrid command, Stata Journal, 2017, 17(1):89-115, http://dx.doi.org/10.1177/1536867X1701700106.

35. Allison PD, Fixed Effects Regression Models, Thousand Oaks, CA: SAGE Publications, 2009.

36. Dieleman JL and Templin T, Random-effects, fixed-effects and the within-between specification for clustered data in observational health studies: a simulation study, PLOS ONE, 2014, 9(10):e110257, http://dx.doi.org/10.1371/journal.pone.0110257. 
37. Ela EJ and Budnick J, Non-heterosexuality, relationships and young women's contraceptive behavior, Demography, 2017, 54(3):887-909, http://dx.doi.org/10.1007/s13524017-0578-y.

38. Barber JS et al., The dynamics of intimate partner violence and the risk of pregnancy during the transition to adulthood, American Sociological Review, 2018, 83(5):1020-1047, http://dx.doi.org/10.1177/0003122418795856.

39. Lesthaeghe RJ and Neidert L, The second demographic transition in the United States: exception or textbook example? Population and Development Review, 2006, 32(4):669-698, http://dx.doi.org/10.1111/j.1728-4457.2006.00146.x.

40. Miller WB and Pasta DJ, A model of fertility motivation, desires and expectations early in women's reproductive careers, Social Biology, 1988, 35(3-4):236-250, http://dx.doi.org/ 10.1080/19485565.1988.9988704.

41. Fagan J and Palkovitz R, Coparenting and relationship quality effects on father engagement: variations by residence, romance, Journal of Marriage and the Family, 2011, 73(3):637-653, http://dx.doi.org/10.1111/j.1741-3737.2011.00834.x. 


\section{Authors' affiliations}

Jennifer S. Barber is professor, Department of Sociology, and Yasamin Kusunoki is assistant professor, School of Nursing - both at the University of Michigan, Ann Arbor. Warren Miller is director, Transnational Family Research Institute, Aptos, CA. Sarah R. Hayford is professor, Department of Sociology, The Ohio State University, Columbus. Karen Benjamin Guzzo is professor, Department of Sociology, Bowling Green State University, Bowling Green, $\mathrm{OH}$.

\section{Acknowledgments}

This research was supported by grants R03 HD HD077051 and R01 HD078412 from the Eunice Kennedy Shriver National Institute of Child Health and Human Development (NICHD), as well as NICHD grants to the University of Michigan's Population Studies Center (R24 HD041028), The Ohio State University's Institute for Population Research (P2C-HD058484) and Bowling Green State University's Center for Family and Demographic Research (R24 HD050959). The data used in this analysis were collected with the support of grants R01 HD050329 and R01 HD050329-S1 from NICHD. The authors gratefully acknowledge Robert Melendez for programming assistance, N.E. Barr for editing and the Survey Research Operations unit at the Survey Research Center of the Institute for Social Research for help with data collection, particularly Vivienne Outlaw, Sharon Parker and Meg Stephenson. The authors also acknowledge the intellectual contributions of the other members of the original Relationship Dynamics and Social Life study project team-Heather Gatny, William Axinn, Mick Couper and Steven Heeringa, as well as the Advisory Committee for the project-Larry Bumpass, Elizabeth Cooksey, Kathie Harris and Linda Waite.

Author contact: jebarber@umich.edu 
TABLE 1. Selected pregnancy desire and intimate relationship and control variables among ever-partnered women participating in the Relationship Dynamics and Social Life study, by weekly interview, relationship and respondent, Michigan, 2008-2012

Measure

\begin{tabular}{lll} 
Mean or \% & & \\
\hline Weekly & Relationships & Women \\
interviews & $(\mathrm{N}=2,564)$ & $(\mathrm{N}=895)$ \\
$(\mathrm{N}=32,754)$ & &
\end{tabular}

Pregnancy desire

Any desire in the next mo.

Intimacy, commitment and duration

Relationship type

Engaged/married

Cohabiting

Stayover

Committed dating

Infrequent committed dating

Uncommitted dating

Casual

Heterosexual sexual intercourse

Mean relationship duration (yrs.; range, 0.01-4.0)

Mean age at baseline (yrs.; range, 18.1-20.3)

8

54

na

na

\section{Conflict and asymmetry}

Churning

Nonmonogamy

Mean partner-dominated decision making (range, -1 to 1 )

Threats of assault

Physical assault

Mean age difference (mos.; range, -5.9 to 33.2)

Education difference

Partner has more education

Equal education

Partner has less education

\section{Partner}

Mean partner's education (yrs.; range, 10-14)

Couple's births

Neither had prior birth

Couple had prior birth together

Woman had birth with prior partner

Partner had birth with prior partner

$\begin{array}{cll}3 & 25 & 46 \\ 2 & 19 & 28 \\ -0.02(0.2) & 0.05(0.4) & 0.21(0.4) \\ 1 & 6 & 14 \\ 1 & 6 & 17 \\ \text { na } & 2.2(3.6) & \text { na } \\ & & \\ \text { na } & 17 & \text { na } \\ \text { na } & 41 & \text { na } \\ \text { na } & 42 & \text { na }\end{array}$

na

$12.5(1.1) \quad$ na

na

72

75

na

15

na

5

17

na
30

45

51

75

64

51

54

87

na

$19.2(0.6)$

\section{Individual}

This article is protected by copyright. All rights reserved. 
Black

Highly religious

na

na

na

34

Did not grow up with two parents

na

na

57

Mother had a teenage birth

na

Mother's education $<$ high school

na

Received public assistance in childhood

na

na 47

Mean high school grade point average (range, 0.0-4.2)

na

Received public assistance at baseline

na

na

na 36

Age at first sex $\leq 16$

na

na

36
9

Had $>2$ sex partners

na

na

na

na

37

Ever had sex without contraceptives

Had prior pregnancy

na

na

$62.1(42.1)$

Notes: Figures in parentheses are standard deviations. na=not applicable. 
TABLE 2. Odds ratios (and 95\% confidence intervals) from logistic regression analysis (using within-between specification) assessing associations between reporting any pregnancy desire in the next month and selected variables

\begin{tabular}{|c|c|c|c|c|}
\hline \multirow[t]{2}{*}{ Measure } & \multicolumn{2}{|l|}{ Model 1: Woman level } & \multicolumn{2}{|c|}{ Model 2: Relationship level } \\
\hline & $\begin{array}{l}\text { Within woman } \\
\text { (across relationships) }\end{array}$ & $\begin{array}{l}\text { Between women } \\
\text { (across averages) }\end{array}$ & $\begin{array}{l}\text { Within relationship } \\
\text { (across time) }\end{array}$ & $\begin{array}{l}\text { Between relationships } \\
\text { (across averages) }\end{array}$ \\
\hline \multicolumn{5}{|l|}{ Intimacy, commitment and duration } \\
\hline \multicolumn{5}{|l|}{ Relationship type } \\
\hline Engaged/married & $9.18(6.07-13.88)^{* * *}$ & $24.50(3.53-170.33)^{* * *}$ & $6.31(3.61-11.02)^{* * *}$ & $326.96(91.64-1,166.48)^{* * *}, \dagger$ \\
\hline Cohabiting & $3.39(2.28-5.05)^{* * *}$ & $1.95(0.26-14.49)$ & $2.50(1.45-4.29)^{* * *}$ & $20.30(5.65-72.90)^{* * *}$ \\
\hline Stayover & $3.69(2.45-5.54)^{* * *}$ & $0.31(0.03-2.89)$ & $3.03(1.75-5.24)^{* * *}$ & $1.77(0.41-7.71)$ \\
\hline Committed dating & $2.34(1.60-3.44)^{* * *}$ & $0.56(0.06-4.90)$ & $1.71(1.00-2.93)^{* *}$ & $5.06(1.39-18.38)^{*}$ \\
\hline Infrequent committed dating & $2.09(1.43-3.05)^{* * *}$ & $1.40(0.16-12.54)$ & $2.06(1.22-3.48)^{* *}$ & $7.54(2.05-27.80)^{* *}$ \\
\hline Uncommitted dating & $1.62(1.05-2.50)^{*}$ & $0.18(0.00-7.32)$ & $1.19(0.68-2.06)$ & $2.42(0.50-11.74)$ \\
\hline Casual (ref) & 1.00 & 1.00 & 1.00 & 1.00 \\
\hline Heterosexual sexual intercourse & $2.03(1.31-3.14)^{* *}$ & $1.99(0.55-7.22)$ & $2.20(1.81-2.67)^{* * *}$ & $3.94(1.85-8.39)^{* * *}$ \\
\hline Relationship duration (yrs.) & $2.13(1.59-2.86)^{* * *}$ & $0.41(0.14-1.24)$ & $4.75(3.00-7.52)^{* * *}$ & $0.63(0.27-1.47)$ \\
\hline Duration squared & $0.76(0.70-0.82)^{* * *}$ & $1.17(0.90-1.53)$ & $0.80(0.73-0.87)^{* * *}$ & $1.07(0.86-1.32)$ \\
\hline Age (yrs.; time-varying) & $1.11(0.98-1.25)$ & $0.82(0.55-1.22)$ & $0.42(0.29-0.60)^{* * *}$ & $1.10(0.81-1.47)$ \\
\hline \multicolumn{5}{|l|}{ Conflict and asymmetry } \\
\hline Churning & $1.20(0.91-1.59)$ & $1.37(0.67-2.82)$ & $1.24(0.92-1.68)$ & $1.72(0.79-3.74)$ \\
\hline Nonmonogamy & $1.55(1.12-2.15)^{* *}$ & $2.78(1.25-6.21)^{*}$ & $0.83(0.51-1.35)$ & $8.63(2.44-30.46)^{* * *}$ \\
\hline Partner-dominated decision making & $1.31(0.90-1.90)$ & $1.48(0.65-3.34)$ & $0.98(0.73-1.31)$ & $1.16(0.48-2.79)$ \\
\hline Threats of assault & $0.93(0.58-1.50)$ & $8.90(2.63-30.16)^{* * *}$ & $0.70(0.44-1.10)$ & $93.53(2.73-3,207.80)^{*},+$ \\
\hline Physical assault & $1.92(1.15-3.19)^{*}$ & $0.45(0.14-1.49)$ & $1.15(0.69-1.91)$ & $0.06(0.00-5.31)$ \\
\hline Age difference (mos.) & $0.98(0.95-1.01)$ & $1.08(1.00-1.18)$ & 1.05 & $8-1.12)$ \\
\hline \multicolumn{5}{|l|}{ Education difference } \\
\hline Partner has more education & $1.46(0.98-2.16)$ & $1.26(0.51-3.09)$ & 1.94 & $8-3.84)$ \\
\hline Equal education (ref) & 1.00 & 1.00 & 1.00 & \\
\hline Partner has less education & $0.65(0.45-0.96)^{*}$ & $0.52(0.27-1.01)$ & 0.49 & $8-0.86)^{*}$ \\
\hline \multicolumn{5}{|l|}{ Partner } \\
\hline Partner's education (yrs.) & $1.19(0.99-1.41)$ & $0.66(0.48-0.91)^{*}$ & 0.64 & $0-0.84)^{* * *}$ \\
\hline Couple's births & & & & \\
\hline
\end{tabular}

This article is protected by copyright. All rights reserved. 
Neither had prior birth (ref)

Couple had prior birth together

Woman had birth with prior partner

Partner had birth with prior partner

\section{Individual}

Black

Highly religious

Did not grow up with two parents

Mother had a teenage birth

Mother's education $<$ high school

Received public assistance in childhood

High school grade point average

Received public assistance at baseline

Age at first sex $\leq 16$

Had $>2$ sex partners

Had prior pregnancy

\section{Repeated measurement}

Total no. of weekly surveys completed
1.00
$0.36(0.20-0.64)^{* * *}$
1.00
$0.16(0.08-0.34)^{* * *}$
$1.58(0.59-4.23)$
$0.47(0.15-1.48)$
$0.70(0.48-1.02)$
$3.44(1.09-10.91)^{*}$

1.00

$0.37(0.15-0.89)^{*}$

$0.06(0.02-0.17)^{* * *}$

$1.30(0.59-2.86)$

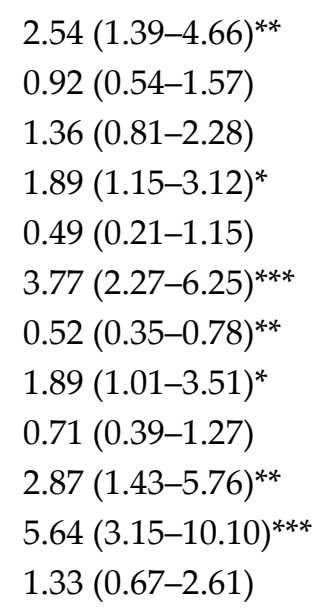

$1.00(0.99-1.01)$

895 (women)

32,754 (weeks)

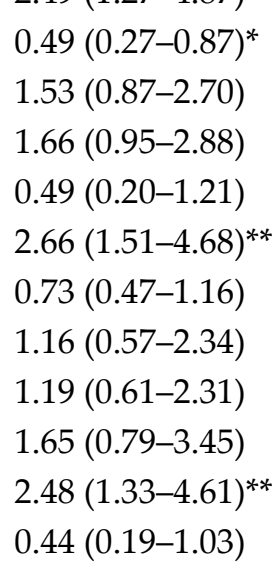

Ever had sex without contraceptives

N

$N$

${ }^{*} \mathrm{p}<.05 .{ }^{* *} \mathrm{p}<.01 .{ }^{* * *} \mathrm{p}<.001$. +Only 43 relationships were classified as ever engaged/married and ever included threats. Thirty-five of them included desire for pregnancy. In other words, the cross-tabulation for these two variables with the dependent variable yielded very small cells. Excluding these variables from the model (i.e., combining engaged/married with cohabiting, and combining threats with physical assault) removes the small cells (and the very large odds ratios), but changes the other numbers in the table very little. Thus, we present these coefficients with the warning that they are estimated on the basis of a small number of relationships. Notes: Two-tailed tests were used in assessing significance. ref=reference group. 